\title{
TRACHOMA*
}

\section{DIAGNOSIS AND TREATMENT}

BY

\author{
LOPES DE ANDRADE \\ Director of the Gama Pinto Ophthalmological Institute and \\ Professor of Medicine, University of Lisbon
}

\begin{abstract}
MEDICAL treatment has undergone revolutionary changes since the recent discovery of many new therapeutic agents, and this progress has been fully shared by ophthalmology. Such advances have unfortunately been accompanied by the appearance, in both scientific and popular periodicals, of quite incredible claims for the therapeutic effect of certain remedies. Trachoma, a widespread and incapacitating disease, has been the subject of many such communications, and surgeons with a limited experience of the condition are left in doubt as to which of a number of chemical and antibiotic agents should be exhibited in their method of treatment.
\end{abstract}

\section{DIAGNosis}

In trachoma, the necessary criteria for its early diagnosis must first be considered, and by this I mean the pathognomonic signs of the disease. The aetiology is still uncertain, and I agree with Duke-Elder (1943) that " at the present time we must admit that the organismal cause of trachoma is unknown". Certain workers, including Thygeson (1934 a, b ; 1937), Thygeson and Proctor (1935), Cuénod and Nataf (1930, 1937), Busacca (1937), and Poleff (1948), have considered this aspect of the disease without conclusively demonstrating the causative agent. Prowazeck's inclusion bodies can be found in other conditions (Gabriélidès, 1927), but their incidence is much higher in trachoma. Of the laboratory examinations, the blood count is of considerable help, and in a large number of cases which I have investigated there has been a remarkably consistent lymphocytosis. If this change occurred early in the disease, and if the patient with trachoma did not tend to have a "lymphatic constitution", the diagnostic value of this observation would be enormous. This, however, is not the case, and the blood picture must be considered in association with other features of the disease, the most important of which are the clinical appearances.

The two most valuable clinical findings in the initial diagnosis are

* Received for publication March 22, 1951. 
granulations and pannus. The granulations are peculiar in structure and are generally seen in the upper fornices, but non-trachomatous granulations may also be observed, which are similar in distribution and of identical morphology even on slit-lamp examination. Incipient pannus is a very important sign, but must not be confused with an increased vascularity of the marginal plexus, nor with corneal vascularization due to other causes. Unfortunately, pannus does not appear in every case of trachoma.

Along with these uncertainties in the initial diagnosis, we must consider the possibility of other conjunctival diseases in which granulations are found. These conditions I include in the large group of "granuloses of the conjunctiva". They are more usually described as the follicular conjunctivitides, but the hyperplasia which can be observed occurs in the adenoid layer of the conjunctiva, and is not a true follicle but a granuloma.

A provisional classification, which I have used myself since 1942, is as follows:

(1) Allergic granuloses associated with
(a) spasmodic coryza or hay fever,
(b) drug irritation (e.g., atropine, eserine, butyn),
(c) chronic infections due to the staphylococcus or Koch-Weeks bacillus,
(d) (in children) benign conjunctival folliculosis.

(2) Irritative granuloses

(a) caused by foreign bodies (e.g., dust of rhyzome of Helleborus odorus),

(b) secondary to skin diseases (e.g., acanthosis nigricans, molluscum contagiosum).

(3) Infective granuloses
(a) Béal's acute granulosis,
(b) Axenfeld's chronic granulosis,
(c) swimming-bath conjunctivitis,
(d) trachoma.

Each of these conditions has characteristic features in the history and symptomatology which assist in the differential diagnosis. In the early stages, however, confusion of other conjunctival diseases with trachoma may occur, and for this reason a number of the therapeutic results reported in the literature are unduly optimistic.

In the early stages of trachoma, when clinical and laboratory findings do not fully substantiate the diagnosis, little help can be given by anatomopathological investigation. As the disease develops, the histological changes which appear are remarkably constant, and do not occur with a similar regularity in the other granuloses. The essential features are the papilla and granulation, and in these two distinct zones are always found:

(1) the central epithelial zone,

(2) the peripheral lymphocytic zone. 


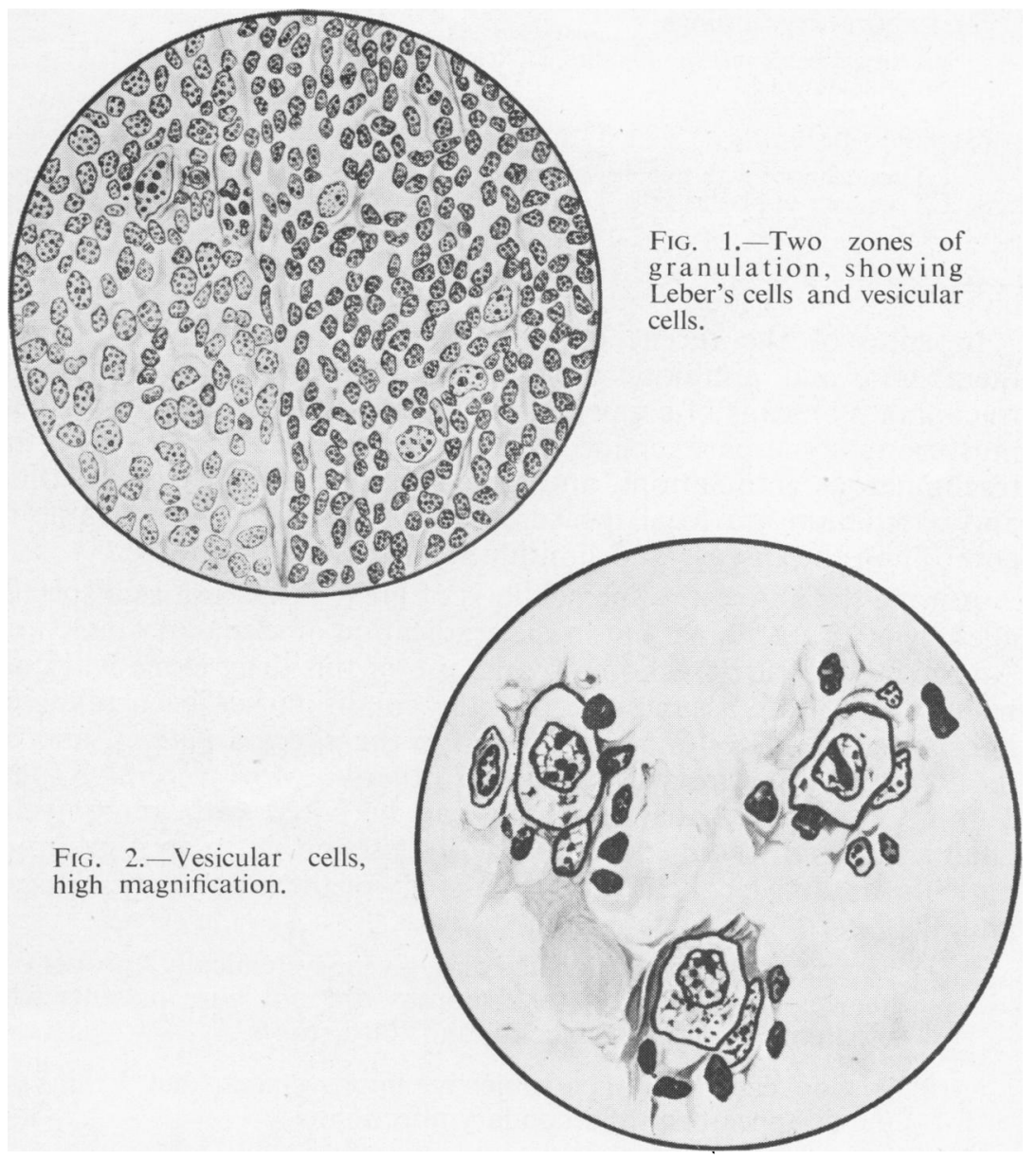

In both zones there are, in addition, three cellular elements: plasma cells, Leber's cells, and vesicular cells (see Figs 1 and 2).*

Thus the diagnosis of early trachoma can be made with fair certainty if the clinical, laboratory, and histo-pathological findings are considered together, the following being the important features in each group:

(1) Clinical findings

(i) granulations in upper part of conjunctival sac,

(ii) incipient pannus,

(iii) early scarring in some cases,

(iv) resistance to the general forms of treatment.

* These were first described by the present author (de Andrade, 1930), and their existence was confirmed n a letter written to me by Redslob. 
(2) Laboratory findings

(i) Prowazeck's inclusion bodies,

(ii) lymphocytosis.

(3) Histo-pathology

(i) granulations with two distinct zones,

(ii) presence of plasma cells, Leber's cells, and vesicular cells.

\section{THERAPY}

In spite of the recent developments of a number of chemotherapeutic and antibiotic preparations, the classical treatment of trachoma by means of copper, silver nitrate, and the sulphonamides, must be in some part retained. The mechanical destruction of the trachomatous granulations, and the action of diathermy coagulation and irradiation are local measures which remain of great value in controlling the disease and limiting its late manifestations.

Among the antibiotics, penicillin is of great value, not as a specific agent against trachoma, but in the eradication of secondary infection. An attempt to cure trachoma by the use of this drug alone will only result in the false assumption that the condition has been rendered harmless; it will continue to develop in the affected patient, and by its contagious nature will spread to others. More recently, some authors have stated that trachoma can be cured with aureomycin. I have personally studied the effect of this antibiotic on a group of patients, and have concluded from a study of the laboratory, clinical, and histo-pathological data that

(1) aureomycin applied locally and given systemically for periods varying from 10 days to 2 months did not cure patients with trachoma in the first, second, and third stages,

(2) in most cases there is a subjective improvement, due, I think, to the disappearance of secondary infection,

(3) when the conjunctival granulations were improved or cured by aureomycin, they were not in fact of trachomatous origin.

These findings were presented in the Trachoma Section of the XVI International Congress of Ophthalmology, London, 1950 (de Andrade, 1949).

In conclusion, I should like to present a simple scheme which has been in use for some years at the Instituto Oftalmologico de Lisbóa for the treatment of trachoma in its various stages.

InVASION PERIOD.-If there is much secretion, the tarsal conjunctiva is painted with a 1 per cent. solution of silver nitrate, and is cauterized three times a week with a copper sulphate pencil. The silver nitrate may be replaced by aureomycin drops used 2-hourly. At night, penicillin jelly, noviform, or boric acid is introduced into the conjunctival sac. 
INTERMEDIATE STAGE.-In the presence of corneal lesions and pannus, sulphonamides should be given systemically, and atropine locally, in conjunction with penicillin or noviform. As soon as improvement becomes evident, the mechanical destruction of the trachomatous tissue should be undertaken, especially in the recesses of the superior fornix, and cautious cauterization with copper sulphate may also be employed.

Cicatricial Stage.-Secondary infections are dealt with by the usual methods, and yellow oxide of mercury in jelly, and vitamin A preparations may be used in addition, the latter to resist the tendency to xerosis. Copper sulphate in glycerol is another preparation of value. Fibrous contractures of the lids should be treated surgically.

This is a simple scheme that may easily be altered in accordance with the knowledge and experience of the ophthalmic surgeon treating the case, taking into account the progress of the disease and the personal reaction of the patient. The following Table shows the types of treatment available at various stages of the disease.

TABLE

TYPES OF THERAPY AT VARIOUS STAGES OF TRACHOMA

\begin{tabular}{ll|l|l}
\hline Medical & $\ldots$ & $\ldots$ & $\ldots$
\end{tabular}

More recently I have used diathermy coagulation in conjunction with the instillation of cortisone over a period of 8 days for the destruction of granulation tissue. The cortisone has, of course, no curative action in trachoma, but it does reduce the inflammatory reaction which normally follows diathermy coagulation. It is 
found in this condition, as in other ocular inflammations, that cortisone is more effective when there is a preponderant allergic factor. In some cases of trachoma, where there is an associated diffuse iritis, this anti-allergic action of cortisone may be of especial value. To prevent secondary infection, penicillin jelly may be used in conjunction with the diathermy coagulation and cortisone. The results of this recent development in treatment seem to me to be satisfactory, but it is still too early to form a definite opinion.

I should like to thank the Lederle Laboratories of America for their help in providing aureomycin for this investigation.

\section{REFERENCES}

De ANDrade, Lopes (1930). Ann. Oculist., Paris, 167, 1027. (1949). Arq. portug. Oftal.

BusaccA, A. (1937). Arch. Ophthal., Chicago, 17, 117.

CUÉNOD, A., and NATAF, R. (1930). Rev. int. Trachome, 7, 13. (1937). British Journal of Ophthalmology, 21, 309.

Duke-Elder, W. S. (1943). "Text-book of Ophthalmology", vol. 2, p. 1599. Kimpton, London.

GABRIÉlidès (1927). Rev. int. Trachome, 4, 80.

POLEFF, L. (1948). Docum. ophthal., 2, 297.

Thygeson, P. (1934a). Arch. Ophthal., Chicago, 11, 728. (1934b). Ibid., 12, 307. (1937). Ibid., 17, 18.

and Proctor, F. I. (1935). I Ibid., 13, 1018. 